\title{
Diseases and Disparities: The Impact of COVID-19 Disruptions on Sexual and Reproductive Health Services Among the HIV Community in India
}

\author{
Neha Parikh ${ }^{1}$ - Angela Chaudhuri ${ }^{1} \cdot$ Syama B. Syam ${ }^{1} \cdot$ Pratishtha Singh $^{1} \cdot$ Prachi Pal $^{2} \cdot$ Praneeth Pillala $^{3}$
}

Received: 19 December 2020 / Revised: 27 October 2021 / Accepted: 28 October 2021 / Published online: 20 January 2022

(c) The Author(s), under exclusive licence to Springer Science+Business Media, LLC, part of Springer Nature 2021

\begin{abstract}
People with HIV navigate numerous challenges to access healthcare in India. The lockdown in response to the COVID-19 pandemic presents further challenges in accessing sexual and reproductive health (SRH) services. This research explored the impact of the pandemic on SRH services, and the depth of disruptions faced by people living with HIV (PLHIV) in accessing treatment. Using purposive sampling with maximum variation technique, we recruited and conducted 150 telephonic indepth interviews with PLHIV and HIV care providers (HCPs) from five states in India (Karnataka, Tamil Nadu, Maharashtra, Andhra Pradesh, and Telangana). The interviews were recorded, transcribed, coded, and analyzed using interpretative phenomenological analysis. Five main themes were identified: the effect of COVID-19 on (1) access to care, (2) quality of care, (3) social determinants of health, (4) system and community resilience, and (5) support required to address population-specific vulnerabilities. Despite the availability of free government treatment services during the pandemic, profound disruptions in the SRH services, particularly antiretroviral therapy and HIV care, were reported by PLHIV and HCPs. This qualitative study revealed how existing inequities in HIV treatment and care are exacerbated by the pandemic. These findings highlight that the pandemic response should be community-centered to prevent extreme disruptions in healthcare which will have a disastrous effect on the lives of PLHIV.
\end{abstract}

Keywords HIV · COVID-19 - Sexual and reproductive health services

\section{Introduction}

India has the third largest HIV population, with over 2.1 million persons infected with HIV since 2016 (UNAIDS, 2014). In order to maintain optimal quality of life, it is essential for PLHIV to have consistent and quality engagement with the health system. This makes health services vital for people infected with HIV because untreated HIV, overtime, damages the immune system. The under-funded health in the public sector in India, of less than $1.4 \%$ of the gross domestic

Neha Parikh

parikh.neha@gmail.com

1 Swasti Health Catalyst, 25, 3rd Floor, Raghavendra Nilaya, 1st Main Road, AECS Layout, Ashwathnagar, near Paratha Plaza, Bengaluru, Karnataka 560094, India

2 Institute of Development Studies, University of Sussex, Brighton, UK

3 PCMH Restore Health, Bangalore, India product (Kaul, 2019), suffers from a shortage of public services and a poor infrastructure leading to concerns of poor quality, unavailability of appropriate facilities, and an overdependence on the private sector for care.

Despite the Indian government policies that ensure access to ART, a legal right for people diagnosed with HIV (NACO, 2017), the national budget for eliminating HIV has been steadily decreasing over time (Express Web Desk, 2017). Data further show that progress toward the global targets is stalling with HIV prevention and treatment services failing to reach at-risk groups (WHO, 2020). Furthermore, research indicates that HIV transmission rates increase with migration and there are numerous gaps in internal migrants' access to HIV services in India. Migrants with HIV face logistical, linguistic, and cultural barriers and, as a result, are extremely vulnerable to infection and death (Todrys \& Amon, 2009). While structural challenges impede access to HIV prevention and treatment services, PLHIV also face a host of navigational issues within the health system. Prior research shows financial constraints, lack of privacy, and poor quality of 
care are barriers to accessing HIV care or adhering to ART (Kumarasamy et al., 2005; Sahay et al., 2011).

Structural stigma and discrimination further exacerbate healthcare challenges facing PLHIV. A cross-sectional study of over 300 hospital workers in Mumbai and Bangalore found that $50-83 \%$ of the staff believed that those who acquired HIV through sex or drugs "got what they deserved" (Steward et al., 2013). The results also revealed discriminatory attitudes including inclination to discourage women with HIV from having children, endorsement of compulsory testing for female sex workers (FSW), and surgery patients. Stigma has also profoundly shaped the lives of individuals with HIV often resulting in a delay to seek care (Steward et al., 2013). For example, data show that care providers hold stigmatizing views around key HIV populations including considering FSW as promiscuous, a judgmental attitude around drug use, and widespread homophobia and transphobia, resulting in PLHIV receiving poor quality of care and a routinely negative experience with the health system (Chakrapani et al., 2009, 2013; Kar et al., 2018). Research further links exposure to this stigma to low adherence, missed appointments, and irregular prescription refills (Ekstrand et al., 2018). The experiences of PLHIV when seeking treatment greatly influence their willingness to seek future treatment, adhere to medications, and in turn, lead to a higher prevalence of HIV across the country.

\section{The COVID-19 Pandemic in India}

India began its first lockdown on March 24, 2020, to mitigate the spread of COVID-19. The fragile public health systems in India have been strained due to a reallocation of staff and services to manage the pandemic which has impacted HIV treatment accessibility, with emerging reports indicating lower access to HIV medication, treatment, and care for PLHIV (Chattopadhyay, 2020). Limited information, however, is available regarding pandemic-related healthcare disruptions directly experienced by PLHIV and their providers. Past epidemics and global emergencies have often missed addressing risks to vulnerable communities that are not directly affected by the prevailing emergency such as COVID-19. The current study identifies disruptions in care for PLHIV as well as the barriers to seeking care that will be important for the development of mitigation strategies to improve HIV treatment and access during future disruptions. We use a communitycentered participative approach to account for the voices and experiences of the HIV community to better understand the depth of disruption in SRH services during the COVID-19 pandemic.

\section{Aim of Study}

A qualitative study was conducted from a constructivist point of view to generate insights regarding the disruptions experienced by the HIV-positive community trying to access health services during the COVID-19 pandemic and lockdown using an interpretative phenomenological analysis (IPA) approach. The key belief of the constructivist paradigm is that reality is "socially constructed," and therefore special emphasis is given to understanding the individual's perspective and their interpretation of the world around them (Smith \& Osborn, 2009). A constructivist researcher makes meaning of the data through their own critical thinking as well as processing the information derived from their interactive engagement with participants through a series of processes like questioning, listening, writing, reading, and recording (Guba \& Lincoln, 1994). Furthermore, IPA posits that narratives shared by individuals reflect how they make sense of their experiences. Because of its commitment to the detailed examination and interpretation of these lived experiences (Alase, 2017), IPA was chosen as the research approach for this study. Therefore, in-depth interviews with PLHIV as well as their HCPs were used as the primary method of investigation and responses to the interviews were continually analyzed and interpreted to understand and extract meaning of participants' perceptions and experiences. This study was approved by the Catalyst Group Institutional Review Board on July 20, 2020. Participants were informed about the nature and purpose of the study, as well as possible risks, and provided informed consent.

\section{Method}

\section{Participants and Procedure}

To obtain diverse perspectives regarding the extent of disruption to SRH services, the study included PLHIV and a wide range of HCPs. Only members of the community 18 years of age or older using ART or SRH services for at least 6 months before the first lockdown was initiated in India were invited to participate in the study. Invited HCPs were required to provide HIV services for at least 2 years. These inclusion criteria were selected to ensure that the participants and providers had enough experience with, and knowledge of, the current services and health systems.

Purposive sampling, using the maximum variation technique (Benoot et al., 2016), was used to recruit study participants. Thus, we purposely sampled participants from 
different gender, age, and socioeconomic groups to gather diverse perspectives on how people from different settings experienced disruptions. The same rationale was applied while recruiting HCPs which meant that HCPs were sampled from different sectors as well as from different occupations such as outreach workers, nurses, doctors, and laboratory technicians.

While phenomenological approaches are best suited for smaller samples, we have consciously chosen to include a larger and more diverse sample of participants and providers in order to ensure the validity of our findings. Even though homogeneity of the sample is important in IPA, what is more essential is that all participants share a similar experience of the phenomenon being studied along with the context or setting in which it was experienced (Bogdan \& Biklen, 2007). Therefore, it was important to select participants and sites that best help make sense of the central phenomenon explored.

The study was conducted among PLHIV and HCPs in five states in India—Karnataka (KR), Andhra Pradesh (AP), Telangana (TS), Tamil Nadu (TN), and Maharashtra (MH). These states are among the top 15 states in India with a high need for HIV-related services (Sahu et al., 2020). In addition, the number of COVID-19 cases were also high or on a steady rise in these states (Kumar, 2020). Anticipating potential healthcare disruptions due to COVID-19 and the strong working relationship Swasti has with the community-based organizations (CBO) in these locations, we chose to conduct our study in these five states. ${ }^{1}$

Despite the recent changes in attitudes and behaviors toward HIV, there was no definitive way to identify PLHIV at the population level. Since the group remains difficult to access and is made more vulnerable due to the effects of the COVID-19 outbreak and subsequent restrictions it has brought, the study was conducted with the support of CBOs that work closely with the HIV community. Considering the experiences of these CBOs in navigating the health systems and facilitating services for the communities, they were also used to identify HIV providers and other support staff.

\section{Measures}

In-depth interviews were conducted via telephone using a semi-structured interview guide. The interview guide was piloted with two PLHIV and two HCPs to ensure validity of the topics included. The finalized guide was then translated into the local languages for ease of use by the team of interviewers. Data were collected from August to October

\footnotetext{
${ }^{1}$ Swasti is a not-for-profit organization headquartered in Bangalore established in 2002, focusing on achieving health outcomes, especially for socially excluded and marginalized communities.
}

2020. Trained research assistants from the CBOs conducted interviews with participants and provider interviews were conducted by the core research team.

Participants were recruited by the corresponding CBOs in their respective provinces. Each participant was interviewed by a team of two research assistants that served as a facilitator and a moderator. The facilitator explained in detail the nature and purpose of the study, including voluntary participation and measures to ensure confidentiality, and obtained verbal consent from the participant. Those who agreed to participate answered questions via telephone with the interviewer while the moderator took notes. Once the interview was completed, the recording was labeled with the location and participant identification number, electronically transferred to a secure drive location that had restricted access, and deleted from the interviewer's phone. Four participants from $\mathrm{MH}$ and one from TN did not consent to the recording, so only notes were taken and uploaded to the secure drive folder. The procedures for interviewing providers were similar with two exceptions: (1) the interviewer and moderator were members of the research team and (2) occupation of the provider was recorded. The interviews lasted 45-60 min. Of the 160 eligible PLHIV and HCPs, only 150 interviews were conducted as 9 (out of 120) PLHIV and 1 (out of 40) HCP refused to participate. All recordings were transcribed and translated by a team of transcriptionists; $25 \%$ of the transcripts were randomly checked against the original recordings to ensure accuracy.

We used the maximum variation technique to gather as many different perspectives of the experience of healthcare disruptions as possible. While the CBOs recruited PLHIV from different age groups to diversify the sample, the interviews continued until no further information emerged from the participant narratives. This process was followed in all five states. Since HCP interviews were conducted with an aim to validate the PLHIV narratives, the focus of these interviews was to gather variation in perspectives by talking to different types of HCPs in addition to achieving saturation.

\section{Data Analysis}

Interpretative phenomenological analysis was used to analyze and interpret the data. The interview transcripts were uploaded to Dedoose (a cloud-based application for qualitative and mixed-methods research) and the text was coded and analyzed by the research team trained to use the application. The research team read the transcripts multiple times to get a better understanding of the nature of the participant's responses. Extensive memoing was undertaken to note reviewer's observations about the responses as well as their own personal reflections. Careful considerations were given 
to the content of the interview, language used, and emotions expressed by the participants.

Using a process of open coding borrowed from grounded theory (Khan, 2014), the researcher team independently coded each transcript in Dedoose. This was done to ensure that the focus was on the patterns emerging from the text and not interpretations based on existing literary evidence. As the researchers were coding independently and remotely, the codes were given an elaborate description to convey the logic and rationale to the entire team. Codes were assigned to phrases or passages that stood out from the participants' narrative. At this stage careful consideration was given to not interpret what the participant tried to convey or what the researcher thought of the particular excerpt. This process continued till the entire transcript was coded. Once this process was completed, the researcher then re-read the transcript again to modify and refine the initial codes and give it more structure. While analyzing subsequent transcripts, we tried to keep an open mind and ensured that the process was not a simple repetition of applying codes identified from the previous transcripts. As explained before, importance was given to the participants' experience and not the researcher's knowledge.

The next stage in the process was to identify emerging themes from the data and codes. Researchers coded the text and identified relationships between certain codes with similar codes assigned a single category. Once the coding and categorization process was completed, a codebook was generated by exporting codes from Dedoose. The team reviewed this codebook together to identify connections and emerging patterns among the categories based on their similarities. Based on the homogeneity and relationship, the initial codes and categories were clustered together to form themes and were provided with appropriate descriptions and labels. The themes were not identified based on their frequency in the transcripts but on how the emerging themes revealed the communities' experience of disruptions in services. As our analysis became more and more focused, we dropped some of the initial codes as they did not fit with the emerging structure. A final list of the main themes and subthemes were generated after careful deliberation and discussion.

The researchers met frequently via video-conferencing software during the analysis stage to discuss the coding process once each member of the team completed a single transcript. During these meetings, we reviewed and compared each other's codes, critiqued the coding strategy, re-coded, and added codes to already coded transcripts, based on the requirement. The debriefing happened very frequently in the early stages of analysis and once there was established and agreed upon accuracy of coding among the team members, the frequency of meetings reduced.

\section{Results}

A total of 150 participants (111 PLHIV and 39 HCPs) shared their experiences of disruptions during the COVID-19 pandemic. The mean age of PLHIV was $39(\mathrm{SD}=7.35)$ and included 85 women (77\%), 20 men, and 6 transgender persons. Sixty-two (56\%) participants reported that they were unemployed and 49 had one or other form of employment. The 39 HCPs included 17 females (43.6\%), 20 males, and 2 transgender providers. Twenty-four of the HCPs were facility staff (i.e., doctors, nurses, laboratory technicians, counselors, etc.) and 15 were field staff (i.e., outreach workers, program staff, etc.) Twenty-one HCPs (54\%) were working in the public sector; 18 were in the private sector and had an average 13 years $(\mathrm{SD}=5.9)$ of experience working with PLHIV. From the overall analysis of the experiences shared by the participants (both PLHIV and HCPs), five main themes emerged: (1) effect of COVID-19 on access to care; (2) mixed impact of COVID-19 on quality of care; (3) worsened SDoH; (4) system and community resilience; and (5) support required to address population specific vulnerabilities.

\section{Effect of COVID-19 on Access to Care}

\section{Difficulty to Seek Care Due to Lack of Transportation and Police Violence}

The imposition of the lockdown to mitigate the spread of the pandemic resulted in the complete stoppage of transportation services and a strict restriction on mobility. Since most participants relied on public transport to reach ART centers and other care facilities, they reported adopting alternate methods to overcome these challenges. Most reported relying on friends, family, or sometimes even strangers to procure medicines for them. Further, participants asked for lifts, borrowed vehicles, or paid acquaintances to take them to health facilities.

"'Once I had gone in someone's vehicle to get medicines. It feels bad sir, but I had to survive somehow.' Female, 35, TN.

Participants who owned vehicles or used private transport faced harassment from the police in navigating transport challenges. These were in the form of inquisitions, fines, physical, and verbal restraints during lockdown. Participants reported being abused, tortured, and beaten up by police despite having records to prove the need for ART, making healthcare access extremely difficult.

"I have faced many problems during this lockdown for bringing medicines. I have requested my neighbors many times to take me to the hospital and when they 
finally agreed, the police stopped us midway and beat us." Female, 38, AP-TS.

" "...I told the policeman that I have to bring my medicines, so he started interrogating me about which medicines I am taking and why I have to go out to bring them. They were torturing me and when I finally showed them my ART treatment book, even then they didn't allow us to go, and we had to come back." Male, 40, MH.

Even when the official lockdown ended and unlock phases began, participants mentioned that the lack of transportation continued. The prohibitive costs of accessing transport along with the restrictions prevented participants from traveling in groups, and this was reported as another barrier to travel. This resulted in the community walking to the ART centers to seek care or procure their usual medicine supply, even if it took them hours to reach the facilities.

“"There weren't many transport facilities available, so I used to take a walk to the ART centre." Female, 45, MH.

" "The transport facility was tough and costly. Auto would charge us 40 rupees each time. In case we had to engage auto for a round trip, they charged us around 100 rupees. How can we get 100 rupees during lockdown when we couldn't even have tea properly! So, we had to walk to the center.' Female, 46, AP-TS.

\section{Limited ART Services Due to Shortage of Medicines, Testing, Staff, and Supplies}

Once PLHIV were able to navigate travel and related challenges to reach the ART center or other clinics, they still had to face issues related to the availability of staff, supplies, and changes in service delivery mechanisms. Medicine availability was a major problem for the communities during the initial days of lockdown and this resulted in many PLHIV missing ART doses. There was a lack of other supplies like condoms; however, this was soon addressed with the support of CBOs, non-governmental organizations, and ART centers who reached out to PLHIV and delivered medicines and supplies at their doorstep.

"I didn't get medicine for 15 days, because of which I had to go to Kolhapur and from there they told me to go to Miraj, due to which I had to spend 100 Rs... I told the same to Abdul (Sangram NGO). Abdul told me to go to Miraj Hospital from where I will get the medicine, but finally I didn't get the medicine from anywhere."-Female, $\mathrm{MH}$.

"During COVID-19 there were restrictions on travel, so there were no buses due to which people could not go anywhere and also out of the fear of getting infected they did not go out of their houses. We thought PLHIV should not worry over not getting their medicines, so we decided to give it to them voluntarily. We gave them condoms and tablets. If they wanted, they would ask us for more condoms. We would also ask them about their place of residence and deliver the tablets by ourselves."-ICTC Counselor, TN.

The providers ensured continual supply of ART medicines by delivering them door-to-door but that was not possible for some PLHIV as they migrated back to their villages and postal services were unavailable to dispatch the medicines.

"We had disruption in transportation of medications because we have people living with HIV not from the government ART center but our private patients who live outside Karnataka and they were not able to get ART from their state or their city and we were not able to transport because there was no transportation. Though the papers and everything said the Postal Service has opened up and will take the essential drugs, patients should not be deprived of, you know... people with diabetes should get their regular medication, heart disease should get their medications, but nobody mentioned people living with HIV."—Primary care physician, KR.

Another important challenge reported by PLHIV was the unavailability of doctors on visiting the centers. This was either due to doctors being shifted to COVID-19 duty or senior doctors being in vulnerable groups for COVID-19 and following stay-at-home precautions. The interactions patients had at health facilities were also curtailed due to the pandemic. Sometimes this was due to a shortage of staff, but mostly due to precautionary measures for COVID-19 that warranted reduced patient waiting times, limited interactions, and maintaining a physical distance. This, however, also led to PLHIV's perceptions of the lack of quality care.

"When I went there in April, doctors were not available." Female, 35, AP-TS.

"I was not feeling well and suffered due to a boil/ulcer at that time. There was no one to look after, not even a Registered Medical Practitioner or a medical shop. It was quite problematic as I couldn't get treated for that." Female, 39, KR.

All participants reported a shortage of biomedical tests during this time. This was reported as a nonessential service probably due to allowing only emergency services to function, as well as changing systemic priorities to manage COVID-19.

"Previously, they would ask us to see the doctor, but now they say that doctors have gone for COVID-19 duty. So, nothing much they would do and it has been more than a year since I checked my CD4 count. They would say let it be so for a few days and would just provide me with the needed medicines." Female, 46, TN.

"Viral load is a molecular test which is similar to PCR, what we're doing for Covid. Those PCR machines are being used for testing COVID-19, so why do I want to test for HIV where the urgency is not today, but I need to know the diagnosis of this patient for COVID-19 today because he just might deteriorate in two days. So, the urgency is there, so we do not 
have enough equipment, we do not have enough manpower because the viral load or the PCR COVID-19 needs expertise, needs expert people to do it, and not every lab technician can do that. So there's a shortage of manpower, there's machinery shortage." Primary care physician, KR.

There was difficulty in finding care for diseases other than HIV due to the overburden of facilities and doctors with COVID-19 care. Participants found it difficult to seek care for acute illnesses, routine sexual and reproductive health services, or even preexisting chronic conditions. Due to a strict mandate for prescriptions, difficulties were also reported in continuing their usual practice of procuring over the counter medicines from pharmacies for minor illnesses or when they wanted to avoid visiting hospitals or doctors.

"In government hospitals, they said there were so many COVID-19 patients and refused to treat me. I got my COVID19 test done which was negative but didn't get any medicine for my fever. So, it was a big struggle. Earlier, doctors would treat problems like stomach ache or white discharge but now the doctors were not available as they were all busy with COVID-19 duties. Due to these troubles, I was really scared at some point of time. I didn't even have enough money to consult at big or private hospitals outside. Even if I had gone there, they would ask for some tests and let me down, which we can't afford." Female, 43, AP-TS.

"... when I got a fever, I went to the pharmacy to buy medicine. They told me that they will provide medicine only if there is a doctor's prescription." Female, 28, KR.

\section{Hesitancy in Seeking Care Due to Exacerbated Fear and Stigma}

The outbreak of COVID-19, subsequent lockdown, and the precautions imposed to prevent exposure seemed to have a considerable negative impact on the mental health of the communities and influenced their care seeking behavior. Most PLHIV reported a debilitating fear of contracting COVID-19 due to their immunocompromised status. They feared stepping out of their homes or encountering healthcare providers as they were worried about the repercussions it would have on their life and their families. The belief of being at higher risk compared to the general population prevented PLHIV from seeking care from hospitals or ART centers, interacting with others, and engaging in or going out for their jobs. The risk perception was built gradually over the period of lockdown, by hearing about different instances of COVID19-related fatalities happening in their own communities and among friends.

“...because I was scared, I experienced a lot of difficulties buying medicines during the lockdown. I feared going to work also sir... COVID-19 was spread all over, I thought COVID-19 patients might come to hospital, so I stopped going to hospital." Male, 39, KR.
"Actually, I felt bad several times sir. People used to ask me why I travel outside or come to the hospital, because they are scared, I might spread it to them. Nobody has told me directly, but I have heard people talking about this behind my back." Female, 36, KR.

"...They think that if they come to hospital, they might have to take COVID-19 test and what if they are tested positive. If we want to take them for the routine tests also, they are not showing any willingness to come. Initially they were not like that...If they are tested they are afraid that they might take them to a different place/centre." Outreach worker, TN.

"...Initially, when corona started spreading, we were very negligent. After some days, cases started increasing even in nearby villages and people started dying. This created a panic and we got scared. We couldn't go out anywhere either. We were more scared as our immunity is low. To date, there is this fear."-Female, 40, TN.

PLHIV were consumed by fear and in a constant state of anxiety despite efforts by care providers to counsel and support them. This anxiety of contracting COVID-19 coupled with the fear of their HIV status being exposed was crippling enough to prevent PLHIV from seeking health services even when care was available at their homes.

"They had a lot of fear inside because they would think that normally only we have this virus inside us already, what if we step out and get this even after wearing a mask.... Even now, after we gave them counselling and motivation they would be in fear and often call and ask us, talk to us. We have this fear madam, we have kids madam, would feel bad and shed tears, like that also they did, sir." NGO Nurse, AP-TS.

"For female sex workers, transgenders, MSM whose identities were not known, so to reach these people it was difficult. They are already afraid that people from Sanstha (CBO) have come and they will reveal our status in the community. So these people don't take proper services.” NGO staff, MH.

The existence of systemic stigma that PLHIV continually faced when interacting with the health system felt heightened to them due to the pandemic. There were accounts of PLHIV facing renewed stigma from the society because of their additional vulnerability in contracting COVID-19. While PLHIV reported practicing precautionary measures for COVID-19, many perceived the implementation of these precautions at ART centers and clinics and the subsequent attitude change of providers to be exceedingly discriminating. PLHIV felt that they were not being given enough time for consultations and were stigmatized despite following necessary precautions. Measures of social distancing to dispense medication had some ART centers establish queues for patients outside their hospitals. This exaggerated the fear of embarrassment among PLHIV of being exposed or identified by community members and family.

"Before they used to sit and talk for a long time. But in COVID, we thought the crowd would increase, so we sent 
them faster... So they ask us, sir why do you do this? At first you used to spend so much time, now you tell us to move faster." ART Counselor, KR.

"They would not allow us inside the hall and asked us to stand outside. We were asked to show our book standing outside and they gave us medicine while we stood there. We were also scared of contacting corona. They used to treat us in a disrespectful manner even when we followed all kinds of precautions like wearing masks, using sanitizer etc." Female, 46, AP-TS.

"Initially even if it gets late, we used to wait there for a long time and get the tablets from inside... But now they are not taking care of us only. They give us outside in front of everyone. Everyone looks at us and we don't feel comfortable. Even I told the pharmacist, but he didn't listen. Sometimes, our relative passes by and sees us in that line, so I had to hide my face and cover it." Female, 37, TN.

\section{Medication Adherence}

Most PLHIV were very aware of the importance of continuing ART medicines and the negative consequences of poor adherence on their immunity and CD4 counts. This considerably influenced their medicine adherence and brought willingness to navigate the restraints of COVID-19 and subsequent lockdown to ensure continuity. PLHIV participants resorted to getting lifts from strangers to procure medicine from ART centers or depending on family members to pick up their supply. Some participants also reported that the pandemic situation fortified their determination for medicine adherence.

The community efforts were corroborated by HCP reports, when some of them mentioned that PLHIV were willing to travel longer distances to procure medicines to ensure continuity yet maintain anonymity of their status in society. Bulk supply of medicines from the facilities as well as outreach by these organizations also facilitated unchanged ART adherence.

"I have never stopped taking medicines ever since I started with ART. Even, during tough situations I continued to take medicines due to the risks associated with stopping it." Male, $55, \mathrm{KR}$.

"Then I will go to a private hospital or I will ask help from any other organization, but I will not stop taking ART." Male, 35, MH.

"I am regularly taking my medicines. Rather sometimes, I must have taken one extra." Female, 34, TN.

"Even if I don't get one meal of the day, I still need my medicines." Female, 40, MH.

However, the situation was not the same for all, with several PLHIV reporting inability to continue their medicines because of challenges experienced in facilities, unavailability of medicines, and not having any support in procuring medicines.

"I couldn't take medicine for some time. I got the medicine only after visiting the center twice or thrice later." Female, 40, AP-TS.

"Sometimes, they would exchange our medications with someone else, sometimes they will make us wait for 10 days, it was difficult." Female, 40, TN.

PLHIV also shared that the lockdown forced them to migrate to villages where stigma and fear of their status being revealed, dissuaded them from adhering to medicines. This situation continued ranging from days for some to months for others, till they were able to reach out to the center or medicines reached them.

"Many people went to their villages and they were stuck there. So that person thinks that their status is being revealed and hence they won't go to take medicines." NGO staff, MH.

"I had to skip medicine for 15-20 days because I was stuck at my native place...my health further deteriorated due to lack of medicine...I had called our madam and explained my situation. She then arranged a van for me to come back with the help of the police. I received medicines only after that.' Female, 43, AP-TS.

\section{Mixed Impact of COVID-19 on Quality of Care.}

Quality of care delivered during the COVID-19 lockdown was explored from both the PLHIV and the HCP perspectives. While the HCPs' narratives largely focused on how they navigated the challenges and continued providing care despite the hardships, communities provide a mixed perspective on the care they received. Several PLHIV participants reported feeling improved quality of care especially when HCPs reached out to them at their residence to supply medicines and over phones to provide uninterrupted care services.

"In the hospital they treat me properly and take good care of me. No, in fact they are taking care of us better now. They are coming to our area itself and giving us tablets. They are taking good care of us." Female, 40, TN.

"Every time I go to hospital, they treat me with empathy and respect sir, so at chikkaballapur ART care, I am very highly respected and happy to avail treatment from there." Male, 30, KR.

Some PLHIV participants expressed mixed feelings regarding the change in attitudes of HCPs pre- and postCOVID-19, with some reporting feelings of increased discrimination. Additionally, there were some instances where respondents found themselves in difficult situations navigating the complex continuum of private and public healthcare.

"Before Corona, they would at least sit and give counselling for $15 \mathrm{~min}$ but after this, they didn't let us stand. They just asked us to take the medicines and leave, not to crowd 
there. That was difficult. Before, it was different, now the way they treat us is not good. What to do! There is no other place to go so we go and get it." Female, 40, TN.

"I don't use the medicines I received for my sugar problem from the pharmacy. I approached the local MLA for my problem. He ignored me saying he is also facing difficulties and asked me to leave. I then approached the government hospital, brought 10 tablets for 5 rupees, but I could not tolerate them at all. I had a burning sensation in my stomach and a headache after taking them. I visited the local doctor and compared the medicines I used to buy from Bengaluru and the medicines I received in the government hospital. The doctor made statements like- "go to Bengaluru in an airplane and buy those medicines only." That is how they are here. They don't give respect. They are careless. They said it is not just you who is suffering, the whole world is suffering due to COVID-19." Female, 39, KR.

While there was a complete or partial stoppage in care provision at the start of the pandemic due to lockdown and other restraints, once the services started, additional efforts were taken to ensure that the quality of care provided was better than before. Some HCPs, however, did express a feeling of guilt and dissatisfaction of not being able to "do everything" when compared to care delivery prior to the outbreak.

"We are performing better than before. Greater quality has been maintained now. For better quality we need to work harder and because of COVID-19 beneficiaries, we are putting in more efforts. For instance, there is some patient who does not have enough money to travel and comes from far away, so we will send one helper from either VIHAN, TI or PLHIV network who goes to their home, does the checkup and provides them with timely medicines..."- ART counselor, $\mathrm{MH}$.

"With the advent of COVID-19 there are not many CD4 tests done right? Even we feel guilty about it, as a lot of people have passed the schedule of getting their CD4. So what we did was we called them and told them to eat nutritious food and they don't have to worry for the time being, the tests can be done after two months. We have given such counselling to them to focus on their food mostly." ICTC counselor, TN.

While the altruistic sense of duty and responsibility toward the communities kept HCPs motivated, several respondents reported to be in a state of constant anxiety and stress because of the fear of getting infected with COVID-19 and were stressed about carrying it to their family or infecting patients and community members.

"....if I go there they would call me inside but the thought that comes to my mind would be that I have to maintain distance from them because we are exposed to so many places and people like Government Hospitals, so because of us what if they get infected or their children, then that is problematic for them. Or if I get it from them then I am putting my family at stake. Both ways it is problematic. When we maintain distance then they would feel madam was not like this before, why is she acting so weirdly is what some people say to us. Then we will have to explain to them that we go to a lot of places. Some people may say that it's okay even if we get infected but that will be pestering us if we put them at risk." Outreach worker, TN.

An increase in the overall commitment and empathy of HCPs toward community members was reported, evidenced by precautions taken while they visited the PLHIV at their homes or in the community networks and linkages they formed to provide care. The practice of conducting outreach to ensure medicine and rations reach community members on time continued even when they had to spend their own money for travel and amassing supplies. This was even extended to PLHIV who were not registered with their ART centers.

"To patients who are already on ART medicine secretly without letting their family know, we have either directly delivered the ART medicine at home or took help of some NGO. We met them at their place of convenience and delivered medicine sufficient for around 3 months instead of the usual monthly distribution so that they don't have to travel again and again." ICTC counselor, AP-TS.

"..some of them didn't have food to eat and they didn't have money to travel, because most of them were becoming unemployed during that time. So we have provided them with some amount of finance also. We used to deposit some amount in their accounts, after asking their account number, and then they used to come and visit." ART Medical Officer, KR.

"In this time of pandemic, everybody is coming together and working a way out of it. We cansense this togetherness. Everyone working together will also help the ART beneficiary to spend the rest of his life peacefully. On the request of the patient, we send our helper with the medicines. We do this with their consent and by taking them into confidence." ART counselor, $\mathrm{MH}$.

\section{Worsened Social Determinants of Health}

\section{Employment Loss Causing Financial and Food Crisis}

Even when PLHIV navigated transport and access difficulties to seek care, systemic issues prevented them from achieving overall health during the pandemic. Most PLHIV reported extensive disruptions with work because of the imposed lockdown. Daily wage earners and small business owners reported inability to work due to mobility issues and sex workers and transgender persons reported facing problems due to fear among their clients. The pandemic decimated jobs and means of livelihood threatening ill-health and starvation.

"People are not giving anything now and not even talking to us properly. Previously they used to give us money and 
used to take our blessing but nothing is happening now." Transgender, 33, MH.

"Because I lost my job, I was unable to pay the rent, I could not repay the borrowed money, we did not even have food. Then only we got to know that the office was giving the rice and dal. They asked us to collect it from the office, and then we did not even have money for the bus, so we had to borrow. The lockdown for three months had left us into misery."' Female, 36, TN.

"Sex workers used to work and earn from outside before, now it has stopped. They tried asking for housework as cleaners, no one gave them work. Many of them and their families had nothing to eat, and they starved for many days." Outreach worker, KR.

"I used to work in a hotel. It had to remain closed...I did not have money and I could not get medicines too. I walked from street to street, asking people for money and food. I haven't done this any time before." Female, 39, KR.

The pandemic coupled with lack of social support structures precipitated a loss of income and livelihood which reduced access to nutrition and other daily needs for PLHIV. Participants reported extreme difficulties to find access to food and nutritional needs. The loss of livelihood pushed them into dramatic and unprecedented vulnerability, subjecting them to hunger and surmounting debts.

"They told us that you are giving us groceries but how we should cook and asked us to help them with LPG gas services for cooking. But we couldn't arrange gas services for them so we collected money to arrange something as an alternative to gas but still they are facing problems regarding food." NGO staff, MH.

"Madam, I took loans from my surroundings. Now they are asking me to return and it's really difficult now to manage since I have no source of income. The people from whom I have taken debts are constantly threatening me. There is no one to help us financially.' Male, 43, TN.

\section{System and Community Resilience.}

\section{Discontinuance of Government Programs and Support}

PLHIV reflected greatly on the support received or lack thereof from the government, during the ongoing pandemic and the subsequent lockdown. The majority of the PLHIV respondents mentioned there was a lack of formal social protection services or a sudden stoppage of the same during COVID-19. The financial schemes in place for transgender persons, single women, and other vulnerable groups were reported as "paper policies," the benefits of which did not exist, especially when they needed them the most.

"I got my widow pension and Rs. 500 to my bank account during COVID-19. I even got some money for buying cooking gas and scholarships for my kids from the government.' Female, 31, KR.

"I think they should increase pensions. They provide 600 rupees per month, which is not enough to survive life. During lockdown, they stopped giving pensions also, which is a problem sir. Even now I am not getting a pension sir." Male, 39, KR.

"Sir, they used to give bus charge, 60rs, to go to the ART center. Now they've stopped that. They also used to give education funding for the children, they've not given that also. We don't ask them for these benefits. They only give it and drastically stop it. It's very bad. They make fake promises and do injustice to our people. In future this shouldn't happen." Male, 45, KR.

Moreover, HCPs corroborated the same, mentioning a lack of financial aid from the government. They reported that funds to government facilities were delayed since months and HCPs were not given appropriate compensation and incentives for their work.

"In such a rare pandemic situation where experienced health workers like me had to continue working tirelessly, a minimum wage and allowance to maintain his family will be expected. We are not even being recognized properly. Britain like countries have fair recognition to workers like me.' Counselor, AP-TS.

"4 months have gone and now the 5th month is going on, our salaries still haven't been given yet due to COVID-19. We are working without any payment since so long." Project Manager, $\mathrm{MH}$.

\section{Service Delivery Adaptations}

There were extreme disruptions with respect to service delivery which continued for several months in some locations, especially in the initial periods of lockdown. Realizing the urgency of the situation, HCPs came up with novel mechanisms to ensure further disruptions did not occur. The determination and dedication shown by HCPs in continuing service provision to communities despite the challenges they faced is testimony to the investment of HCPs in PLHIV's health and well-being.

"The District Aids Prevention Control Unit instructed us to call each one of our beneficiaries and distribute their medicine. Some mobile numbers were changed and some were not getting connected, so we went to their address directly. We have also faced difficulty since the police stopped us. Then we requested the police saying it's a medical emergency, showed our ID cards and covered almost 95\% of PLHIV. We had planned it in advance and gave them medicine for three months instead of the usual one month so that they don't face any difficulty further during the lockdown period." NGO counselor, AP-TS. 
Extensive outreach was conducted by ART centers, NGO networks, and PLHIV support groups to ensure patient wellbeing and adequate medicine supply. Quick thinking on the part of caregivers to use outreach workers, NGO staff, wellness facilitators, and ART counselors who work very closely with PLHIV helped gain the trust, build rapport, and provide safe spaces for the PLHIV community.

"During lockdown, we distributed medicines to those who came to us and we provided medicines for 2 to 3 months at once according the their CD4 counts, patients with high adherence and good CD4 count, we dispensed medicines for 3 months and those patients with low CD4 count poor adherence we dispensed medicines for 2 months." ART counselor, KR.

Efforts were also made by care centers to provide information to communities regarding the availability and duration of services. Where community members reported unwillingness or inability to travel, they were linked with convenient nearby centers to ensure an uninterrupted supply of medicines and access to care. Telehealth was widely adopted by ART centers and clinics to understand the health conditions of patients who could not come for in-person visits, providing appointments and information regarding medicine delivery as well as service availability.

"Those who were very sick would call us by phone and tell us that they weren't able to come to the ART center, can you please give the medicines? So we used to consult over the phone and ask our outreach workers to go and deliver medicines to them. For those who had fever, cough and body pain, we used to tell them to go to the nearest General Hospital or any PHC and they could call us after they reached there. So, we used to give them the name of the injection and they used to take it from there." ART Medical officer, KR

"In case patients wanted to talk to doctors, we have a person named Netaji, who is a counsellor at ART center. He would connect the patient and doctor on the phone when needed." NGO counselor, AP-TS.

To ensure the safety of community members as well as the staff, additional safety measures like physical distancing, compulsory use of hand sanitizers and masks, and flexible working schedules for staff were introduced. Efforts were also taken to assure the community members that these precautionary measures were intended to safeguard them from getting the virus and not meant as a targeted discriminatory approach.

While the enhanced empathy and initiative taken by HCPs to reach out to the community members were deeply appreciated, members were scared of contracting COVID-19 and expressed concerns with the subsequent changes in care. However, the continuous support from the HCPs and CBOs helped communities understand the situation, overcome the fear and adapt to these changes.
"After the pandemic happened they asked us to wear masks, they gave us sanitizers to apply on our hand; they asked us to maintain distance in the queue while collecting the medicines. They are more precautionary now. These are good for us and we are following the protocols." Female, 37, TN.

"They would be in fear and often call and talk to us. We have this fear madam, we have kids madam, and then they would cry. We would tell the doctor-this woman has a problem like this sir, please take a look at it, sir. And we would tell the patients, sir will be available at this time, you can come and see him, like that we could get them to the doctors, talk and get checked with him." NGO Nurse, AP-TS.

"They also knew about corona, that they have to do social distancing and not roam around aimlessly. And during that time we provided medicines faster and cleared people faster. They used to feel why do they do this but we used to educate them why we have to do what we do, which made them happy." ART counselor, KR.

\section{Communities Becoming Resilient During the Crisis}

Community participants received support from the government, NGOs, civil society organizations, friends, neighbors, and in some situations even strangers. CBOs were considered the most prominent support structures providing rations, delivering medicines, providing counseling support as well as enabling telehealth services wherever possible. The existence of these support systems not only strengthened hope and resilience in communities, but also enabled them to feel compassionate toward others. PLHIV shared instances of making efforts to support other people, despite facing challenging circumstances themselves.

"CBOs called us frequently to know about our status. Informed us about whatever freebies coming from the government. Vegetables, masks etc. were distributed through kits twice. Even if other group members didn't ask about us, CBO kept calling to enquire about us. They also taught us to do thrift saving and the benefit of saving was well understood in this year.' 'Female, 38, AP-TS.

"... The ART center was shifted to another hospital which became a problem for other patients because they got confused where to go. We helped many people to get their medicines, we used to bring their medicines, we also brought a few people to hospital from the rural areas." Female, 36, MH.

"...During lockdown, I helped the other two women who are HIV positive but are not disclosed to anyone, in buying their medicines. When medicines were not available here, I informed Chandru sir at Dandeli hospital and he immediately arranged medicines at the hospital and asked me to collect the medicines from there....I also provided medicines to older people in my community who were restricted from going out during the lockdown." Female, 37, KR. 
"...during these times, we know a person who rides the auto; we borrowed the vehicle from him. He even gave us Rs. 100 for petrol out of his pocket. His name is Pandi, he does not know that I take these medications. So we told them that we were going to Dindigul for some work, so he then told us that there was no fuel in the auto. Then he gave us some money". Female, 36, TN.

HCPs emerged as another strong support system as reported by PLHIV. In addition to being a source of emotional support for them, HCPs went beyond their means to mitigate vulnerabilities faced by communities. The empathetic behaviors ranged from helping PLHIV financially to arranging safe transportation to providing home consultations when possible. This benevolence from HCPs helped PLHIV take ownership of their health. This was practiced by them by adopting safety measures and being vigilant due to their perceived increased susceptibility to COVID-19. They were also cognizant of the importance of continuously taking their ART medicines and made efforts to maintain medicine continuity.

"I think it's our duty to take care of the patient and we have to adapt ourselves to the situation and we have to provide the basic things, some of them didn't have food to eat and they didn't have money to travel, so we have provided them with some amount of finance also. We have put money in their accounts because most of them were becoming unemployed during that time, because most places don't allow labourers to come for work. So many of them didn't have money to come, so we used to deposit some amount in their accounts, after asking their account number, and then they used to come and visit...We have not deposited too much, about 500 or 1000.', Medical officer, KR.

“...Yes Sir, I am aware of the consequences. So, I haven't skipped the medicines any day. I personally enquired in the centre, what if I have to go to the native and forget my tablets in case I need to stay there? They told me that it is mandatory to carry the medicines in advance if I go to native or places where I have to stay away from home. They also informed me that skipping tablets on one day is a complete waste to taking medicines for the whole month and it harms my health, So I never skip it sir." Male, 55, KR.

"...Then the virus will affect the body, and the HIV will grow more, and will make us more sick. More than food, medicine is important." Female, 50, AP-TS.

\section{Support Required to Address Population-Specific Vulnerabilities.}

While the combined effort of support groups and systems coming together did make the communities resilient and helped them cope with the disruptions to some extent, participants expressed concerns that these were not permanent solutions and were unsustainable unless planned and implemented with government support and guidance. To improve access to services, the need for systemic support was felt focused on allocation of travel funds and policies to make commuting easier for caregivers as well as communities. Another recommendation voiced by multiple providers was the need for systematic planning in terms of effective use of available human resources as well as existing care facilities, staff allocations and implementing novel techniques to provide point of care testing for PLHIV.

"The government could have told ART patients to freely travel to the hospitals without any hindrance and take their medicines, they could have given them some transport facility. So, our patients would have reached the ART centers sooner." ART Medical Officer, KR.

"One thing is that travel-wise there should be more amount, Sir! Then, while we go to meet people, the police stopping us, arresting us.... there should be a recommendation for police before only. If a medical staff person is going, so without a question and without stopping the vehicle, they should send, like that" NGO Nurse, AP-TS.

"There should be enough staff for handling the situations. These staff who are already included in any certain programs are shifted to take care of other patients so there will be a lack of expert staff to treat patients especially which is required during such sudden pandemics." ART Counselor, KR.

"If the situation continues like this, then the only option is to organize camps in their areas with all the precautions. It has to be done so that services are easily available for communities." NGO staff, $\mathrm{MH}$.

While the support from local organizations and support groups helped the PLHIV communities cope with finance and food insecurities to some extent, there is a strong unmet need for permanent long-term solutions. Both PLHIV and HCP participants reported provision for a sustained healthy diet as a necessity, owing to their immunocompromised nature. Another notable requirement raised by communities was the need for functional social protection schemes and financial assistance, especially during crises.

"The poor patients should be given proper nutritious food. They are currently being given a pension of 2000 rupees but that is being utilized for some other purpose. So giving them some food material would be better.' ICTC Counselor, AP-TS.

"There were many schemes provided by the government but during COVID-19 all these facilities were stopped, this affected the patients who had to come to the hospital for taking treatments. Initially facilities were provided by the government for food and other essentials, but due to Covid-19, these facilities were completely stopped." ART Counselor, $\mathrm{MH}$.

"CBO was of great help during lockdown... If this can continue to an extent where we get some loans, livelihood, and support! Raise our standard of living so that we do not need to depend on anyone else." Female, 40, AP-TS. 


\section{Discussion}

This qualitative study explored COVID-19 disruptions on SRH services among PLHIV and HCPs. Participants reported significant disruptions in access to care. They faced difficulties due to lack of transportation, financial issues to navigate transport, and challenges with police clearance to access care. This was a unanimous finding from both PLHIV and HCPs. The restrictions imposed as a result of the stayat-home orders issued by the government (BMJ, 2020) had a major impact on the day to day life of PLHIV; from disrupting access to healthcare, to loss of wages and labor (Inamdar, 2020). While there are government run centers in India which provide free treatment and testing services for the community (Beattie et al., 2012), the stringent lockdown measures entirely prevented access to public transport thus cutting off access to essential healthcare services, both from PLHIV and HCPs who depend on public transport. Adding to their vulnerability, the respondents faced police violence when they tried to procure medicines from ART centers, as the implementation of the lockdown, definitions of essential services and the resultant orders given to police were suboptimal (Express Web Desk, 2020). Furthermore, with changes in service delivery, respondents were left dissatisfied because of the limited interaction they had with HCPs, delay in receiving medication and unavailability of tests. Routine non-ART care that involves basic health services was considered nonessential and therefore not prioritized by the health system. This led to closed clinics, shortage, and repurposing of staff that added to the disruptions. All these factors resulted in some PLHIV having an interrupted supply of ART. Our results in India echo similar findings of disruption and anxieties with access to care among PLHIV in other countries (Marbaniang et al., 2020; Shukla \& Ramakant, 2020; Taylor Riley et al., 2020).

Given the dual burden of communicable and non-communicable disease India faces, an urgent need for health system strengthening, and intersectoral collaboration emerges as key learnings from our findings. Modeling studies show that the settings with multiple disease burdens of HIV, tuberculosis, and malaria, healthcare disruptions due to COVID-19 are likely to cause increased deaths over a 5-year period, compared with if there was no pandemic. The greatest impact on HIV was predicted to be from interruption to antiretroviral therapy (ART), due to increased demands on the health system, and the need for maintaining continuity of HIV services was highly prioritized (Hogan et al., 2020). Our study showed that all existing chronic and acute illnesses were considered nonessential during the pandemic and respondents had difficulties to access routine care including SRH services (Taylor Riley et al., 2020).
Our study showed that PLHIV had some understanding of COVID-19 mitigation measures. Because they perceived themselves to be at a higher risk for coronavirus, they adhered to common precaution measures, while simultaneously trying to keep their HIV infection in check. Some participants, however, showed a hesitancy to seek care because they were afraid of additional stigma and loss of anonymity due to social distancing measures such as queuing outside ART centers. The barriers of stigma with HIV have existed in the experiences of care for PLHIV even in the past and were further exacerbated by the pandemic (Ganju \& Saggurti, 2017; Kumarasamy et al., 2005) due to fears of higher vulnerability. For sex workers, transgender persons, and other at-risk groups that rely on daily work (Chakrapani et al., 2011), repeated lockdown and loss of employment have been crippling which resonated with our findings (Sushena et al., 2020).

Despite the multitude of challenges, PLHIV and HCPs showed tremendous resilience in the face of this adversity. HCPs adapted by forming multi-sectoral linkages with private, government, and community-based networks. They tried to ensure that medicine supply was uninterrupted and that PLHIV continued to have access to healthcare services. Services were adapted by ensuring door-to-door deliveries, tele-consultations, and raising of funds to provide food rations. Respondents empathized with their fellow community members to form support structures. Our findings are similar to studies that show vulnerable groups to rely heavily on CBOs in receiving ART, food rations, and emotional support, highlighting the crucial role CBOs play in outreach and access to care, reinforcing the need to collaborate and strengthen these partnerships (Pinto \& Park, 2020; Shukla \& Ramakant, 2020).

The similarities of HIV and COVID-19 in the terms of system preparedness required to control the disease has been echoed by public health experts (Edelman et al., 2020) and was reconfirmed in our findings. COVID-19 challenged the health system in multiple ways and reinforced the need for multi-sectoral effort to prevent disruption in health access, especially for vulnerable groups.

The government in India responded to the looming financial difficulties of the pandemic through financial safeguards: Pradhan Mantri Garib Kalyan Yojana (PMGKY) and the second tranche of the Atmanirbhar Bharat (Bharali et al., 2020). However, there has been criticism for the long-term impact of these measures for the poor, as the PMGKY uses reallocated funds from existing budgets to mobilize this funding (Marbaniang et al., 2020). Our respondents also reported extreme anxiety due to loss of travel allowances which has been reported as a barrier to care (Chawla et al., 2017). There have been requests by PLHIV to be included in Ayushman Bharat to provide social protection support (PTI, 2020). Socioeconomic deprivation that was experienced by our 
respondents can have a long-term impact on mental health and care seeking which is an established phenomenon $(\mathrm{Ng}$ et al., 2014).

While the National AIDS Control Organization had laid out plans to mainstream PLHIV in its strategy (MoHFW, 2021), India's public health system was overburdened even before the COVID-19 pandemic and unable to cater quality care to the population it currently serves (Patel et al., 2021). Investing in the health of those who are HIV-positive is essential. The CBOs and PLHIV who participated in our study relied on charity and donations from well-meaning organizations to function, which does not have long-term sustainability.

To mitigate future disruptions, resilient health systems are crucial. Suggestions considering our findings are as follows. First, promoting ART care and SRH services as essential services is the key to allow both PLHIV and HCPs to travel freely without restrictions. Routine basic health services need prioritization including nutritional supplementation that is vital with ART. Provisions of transportation for healthcare personnel and key vulnerable populations like PLHIV must be maintained. Most respondents were unified in needing support for travel allowances to sustain care in such situations. Second, alliances with CBOs and the private sector need to be further strengthened and supported by the government. This will allow us to build alternate supply chains, innovate with care giving (such as tele-health), and make care more accessible to PLHIV.

Third, the need for universal healthcare coverage has never been greater. While state schemes exist for the PLHIV for food security, nutrition, employment, entrepreneurship, and health (NACO, 2012), our findings show that measures did not reach the PLHIV. This highlights the need to make concerted efforts to mainstream their needs and presents an area of further research to explore how these schemes will be able to improve the social determinants of health for PLHIV. More and more HCP networks and populations need to be brought under the umbrella of Ayushman Bharat. This would allow Ayushman Bharat to move from a mere financial protection scheme to a strategic purchasing tool that can ensure quality and equitable healthcare for all (Chalkidou et al., 2019).

Lastly, structural problems that have plagued India's healthcare system need to be addressed (Gopichandran, 2019). India's gross domestic product (GDP) spending on health makes it very difficult to address these structural issues. Past budgetary changes have reduced funding from existing programs like National Health Mission and redirected them (Prasad \& Sengupta, 2019). NACO reported new infection rates rising for the first time in 2018 with reports of the program not getting full funding (Rao, 2018). The government-funded HIV program saw a drop in allocation to Rs 1,300 crore from Rs 1,700 crore in 2014 (Rajagopal, 2017). Without increase in GDP spending, the structural issues that weaken the public health system will not be addressed (Prasad \& Sengupta, 2019).

Our study represents efforts to qualitatively identify disruptions among the HIV community during the pandemic. It is among the first large-scale studies to entirely rely on digital means to collect, collate, and triangulate qualitative data. Our study comes at a time when it is extremely important to add voices of the community. This study also highlights key disruptions in HIV care, but future studies are needed to identify and understand the causes. These findings must, however, be considered in light of the limitations. Our data rely on sampling HIV-positive participants who are linked to CBOs which may lead participants to present themselves in a particular way. Additionally, the respondents could be influenced by poor recall or selective memory; however, we do not believe that these factors would polarize responses to influence study findings. Finally, we also recognize that the research team's previous experience and subject knowledge could also have influenced the coding, analysis, and interpreting of data to some extent, despite our coding protocols.

\section{Conclusion}

There are several challenges PLHIV in India face when navigating the complex health system, but it is critical that HIV clinical services are centered toward addressing the needs of the community. Pandemics and health system demands will only increase in the globalized world we live in today. Investments for vulnerable groups like PLHIV need systemic support not only in terms of health, but also nutrition, transport, and upliftment of overall social determinants that keep them marginalized. The response to the pandemic should be people centered rather than disease centered. By making concerted efforts to provide equitable health for vulnerable populations like the PLHIV, we can prevent systemic disruptions that can have calamitous lasting effects on their lives.

Acknowledgements The authors would like to thank Dr. Jonanthan Garcia, Oregon State University, for his valuable suggestions to the manuscript. We would also like to thank Hareesh Bokkahalli Siddegowda and Kallana Gowda for their support in coordinating the interactions with the community-based organizations.

Author Contributions All authors contributed to the study conception and design. Material preparation, data collection, and analysis were performed by NP, SBS, AC, PS, PP, and PrP. The first draft of the manuscript was written by NP, SBS, and PS and all authors commented on the latter versions of the manuscript. The final version was critiqued by $\mathrm{AC}$ and all authors read and approved it.

Funding None.

Availability of Data and Material The original data collected from the participants in this study and associated materials are available with the corresponding author. These will be made available upon request. 


\section{Declarations}

Conflicts of interest The authors declare that they have no competing interests.

Ethics Approval Approval was obtained from the Catalyst Group Institutional Review Board. All procedures used in this study pertaining to human participants adhere to the tenets of the Declaration of Helsinki.

Informed Consent Verbal consent was sought for participation and publishing of research findings from all individual participants included in the study.

\section{References}

Alase, A. (2017). The interpretative phenomenological analysis (IPA): A guide to a good qualitative research approach. International Journal of Education and Literacy Studies, 5(2), 9. https://doi.org/ 10.7575/aiac.ijels.v.5n.2p.9

ART Treatment I National AIDS Control Organization I MoHFW I GoI. (n.d.). ART treatment. Retrieved June 25, 2021, from http://naco. gov.in/treatment

Beattie, T. S. H., Bhattacharjee, P., Suresh, M., Isac, S., Ramesh, B. M., \& Moses, S. (2012). Personal, interpersonal and structural challenges to accessing HIV testing, treatment and care services among female sex workers, men who have sex with men and transgenders in Karnataka state, South India. Journal of Epidemiology and Community Health, 66(2), 42-48. https://doi.org/10.1136/ jech-2011-200475

Benoot, C., Hannes, K., \& Bilsen, J. (2016). The use of purposeful sampling in a qualitative evidence synthesis: A worked example on sexual adjustment to a cancer trajectory. BMC Medical Research Methodology, 16. https://doi.org/10.1186/s12874-016-0114-6

Bharali, I., Kumar, P., Selvaraj, S., Mao, W., Ogbuoji, O., Hille, H., Yamey, G. (2020). India's policy response to COVID-19. The Center for Policy Impact in Global Health. Policy Report: 2020. Available at: http://centerforpolicyimpact.org/our-work/the-4ds/ indias-policy-response-to-covid-19/

BMJ. (2020). Covid-19: India should abandon lockdown and refocus its testing policy, say public health specialists. British Medical Journal, 370. https://doi.org/10.1136/bmj.m3422

Bogdan, R., \& Biklen S.K. (2007). Qualitative research for education: An introduction to theories and methods (5th ed.). Laureate Education Inc. https://www.pearson.com/us/higher-education/program/ Bogdan-Qualitative-Research-for-Education-An-Introduction-toTheories-and-Methods-5th-Edition/PGM125872.html

Chakrapani, V., Newman, P. A., Shunmugam, M., Kurian, A. K., \& Dubrow, R. (2009). Barriers to free antiretroviral treatment access for female sex workers in Chennai, India. AIDS Patient Care and STDs, 23(11), 973-980. https://doi.org/10.1089/apc.2009.0035

Chakrapani, V., Newman, P. A., Shunmugam, M., \& Dubrow, R. (2011). Barriers to free antiretroviral treatment access among kothi-identified men who have sex with men and aravanis (transgender women) in Chennai, India. AIDS Care, 23(12), 1687-1694. https://doi.org/ 10.1080/09540121.2011.582076

Chakrapani, V., Velayudham, J., Shunmugam, M., Newman, P. A., \& Dubrow, R. (2013). Barriers to antiretroviral treatment access for injecting drug users living with HIV in Chennai, South India. AIDS Care, 26(7), 835-841. https://doi.org/10.1080/09540121. 2013.861573

Chalkidou, K., Jain, N., Cluzeau, F., \& Glassman, A. (2019). Modicare post-election: Recommendations to enhance the impact of public health insurance on UHC goals in India. Center For
Global Development. https://www.cgdev.org/publication/modic are-post-election-recommendations-enhance-impact-publichealth-insurance-uhc-goals

Chattopadhyay, S. (2020). India's COVID-19 lockdown hits HIV+ and chronic patients hard. Coronavirus Pandemic News I Al Jazeera. https://www.aljazeera.com/news/2020/3/30/indiascovid-19-lockdown-hits-hiv-and-chronic-patients-hard

Chawla, S., Shringarpure, K., Modi, B., Sharma, R., Rewari, B. B., Shah, A. N., Verma, P. B., Dongre, A. R., \& Kumar, A. M. V. (2017). Why are HIV-infected people not started on antiretroviral therapy? A mixed-methods study from Gujarat, India. Public Health Action, 7(3), 183-192. https://doi.org/10.5588/pha.16. 0108

Edelman, E. J., Aoun-Barakat, L., Villanueva, M., \& Friedland, G. (2020). Confronting another pandemic: Lessons from HIV can inform our COVID-19 response. AIDS and Behavior, 24(7), 19771979. https://doi.org/10.1007/s10461-020-02908-z

Ekstrand, M. L., Bharat, S., \& Srinivasan, K. (2018). HIV stigma is a barrier to achieving 90-90-90 in India. The Lancet HIV, 5(10), e543-e545. https://doi.org/10.1016/s2352-3018(18)30246-7

Express Web Desk. (2017). What is HIV/AIDS Bill? All your questions answered. The Indian Express. https://indianexpress.com/article/ what-is/hiv-aids-bill-passed-parliament-lok-sabha-nadda-discr imination-4611167/

Express Web Desk. (2020). Delhi top cop admits to misconduct by police during lockdown; harassment reported from across country. National Herald. https://www.nationalheraldindia.com/india/ delhi-top-cop-admits-to-misconduct-by-police-during-lockdownharassment-reported-from-across-country

Ganju, D., \& Saggurti, N. (2017). Stigma, violence and HIV vulnerability among transgender persons in sex work in Maharashtra, India. Culture, Health \& Sexuality, 19(8), 903-917. https://doi. org/10.1080/13691058.2016.1271141

Gopichandran, V. (2019). Ayushman Bharat National Health Protection Scheme: An ethical analysis. Asian Bioethics Review, 11(1), 69-80. https://doi.org/10.1007/s41649-019-00083-5

Guba, E. G., \& Lincoln, Y. S. (1994). Competing paradigms in qualitative research. In N. K. Denzin \& Y. S. Lincoln (Eds.), Handbook of qualitative research (pp. 105-117). Sage Publications, Inc. https:// psycnet.apa.org/record/1994-98625-005

Hogan, A. B., Jewell, B. L., Sherrard-Smith, E., Vesga, J. F., Watson, O. J., Whittaker, C., \& Hallet, T. B. (2020). Potential impact of the COVID-19 pandemic on HIV, tuberculosis, and malaria in lowincome and middle-income countries: a modelling study. Lancet Global Health, 8, E1132-E1141. https://doi.org/10.1016/S2214109X(20)30288-6

Inamdar, N. (2020). Coronavirus lockdown: India jobless numbers cross 120 million in April. BBC News. https://www.bbc.com/news/ world-asia-india-52559324

Kar, A., Mukherjee, S., Ventriglio, A., \& Bhugra, D. (2018). Attitude of Indian medical students towards homosexuality. East Asian Archives of Psychiatry, 28, 59-63. https://doi.org/10.12809/eaap1 81728

Kaul, R. (2019, November 1). India's public spending on healthcare continues to remain lowest globally. Hindustan Times. https:// www.hindustantimes.com/india-news/india-s-public-health-spend ing-lagging-behind/story-6YPZFSfWMVlHGipDXyUEFO.html

Khan, S. N. (2014). Qualitative research method: Grounded theory. International Journal of Business and Management, 9. https://doi. org/10.5539/ijbm.v9n11p224

Kumar, S. (2020, September 27). India's 10 states with highest number of Covid-19 cases. The Hindustan Times. https://www.hindustant imes.com/india-news/india-s-10-states-with-highest-number-ofcovid-19-cases/story-cm5H3u8ihxCBU9jCeIel9N.html

Kumarasamy, N., Safren, S. A., Raminani, S. R., Pickard, R., James, R., Krishnan, A. S., Solomon, S., \& Mayer, K. H. (2005). Barriers 
and facilitators to antiretroviral medication adherence among patients with HIV in Chennai, India: A qualitative study. AIDS Patient Care and STDs, 19(8), 526-537. https://doi.org/10.1089/ apc.2005.19.526

Marbaniang, I., Sangle, S., Nimkar, S., Zarekar, K., Salvi, S., Chavan, A., Gupta, A., Suryavanshi, N., \& Mave, V. (2020). The burden of anxiety among people living with HIV during the COVID-19 pandemic in Pune, India. BMC Public Health, 20. https://doi.org/ 10.1186/s12889-020-09656-8

NACO (2012). Compilation of the Social Welfare Schemes accessed by PLHIV and HRG. http://www.naco.gov.in/sites/default/files/Natio nal_\%20Report_Social_Welfare_Scheme.pdf

NACO (2017). National Strategic Plan for HIV/AIDS and STI, 201724- Paving Way for an AIDS Free India. http://naco.gov.in/natio nal-strategic-plan-hivaids-and-sti-2017-24

Ng, E., Muntaner, C., Chung, H., \& Eaton, W. W. (2014). Socioeconomic status and mental illness. In: The Wiley Blackwell encyclopedia of health, illness, behavior, and society. https://doi.org/10. 1002/9781118410868.wbehibs570

Patel, V., Mazumdar-Shaw, K., Kang, G., Das, P., \& Khanna, T. (2021). Reimagining India's health system: A Lancet Citizens' Commission. The Lancet, 397(10283), 1427-1430. https://doi.org/10.1016/ s0140-6736(20)32174-7

Pinto, R. M., \& Park, S. (2020). COVID-19 pandemic disrupts HIV continuum of care and prevention: Implications for research and practice concerning community-based organizations and frontline providers [Editorial]. AIDS and Behavior, 24, 2486-2489.

Prasad, V., \& Sengupta, A. (2019). Perpetuating health inequities in India: Global ethics in policy and practice. Journal of Global Ethics, 15(1), 67-75. https://doi.org/10.1080/17449626.2019.15825 53

PTI. (2020). HIV-infected persons appeal to PM to include them in Ayushman Bharat scheme. Deccan Herald. https://www.decca nherald.com/national/north-and-central/hiv-infected-personsappeal-to-pm-to-include-them-in-ayushman-bharat-scheme811854.html

Rajagopal, D. (2017). Payment delays by NACO causing HIV drugs scarcity. The Economic Times. https://economictimes.indiatimes. $\mathrm{com} /$ industry/healthcare/biotech/pharmaceuticals/paymentdelays-by-naco-causing-hiv-drugs-scarcity/articleshow/57503 $550 . c m s ? u t m \_s o u r c e=$ contentofinterest\&utm_medium $=$ text $\&$ utm_campaign $=$ cppst

Rao, J. P. (2018). AIDS control in India losing momentum. The HinduBusiness Line https://www.thehindubusinessline.com/opinion/ is-ending-aids-by-2030-a-receding-target/article25229322.ece

Riley, T., Sully, E., Ahmed, Z., \& Biddlecom., A. (2020). Estimates of the potential impact of the COVID-19 pandemic on sexual and reproductive health in low- and middle-income countries.
International Perspectives on Sexual and Reproductive Health, 46, 73-76.

Sahay, S., Joglekar, N., Jain, R., Potdar, R., Paranjape, R., Rahane, G., \& Reddy, K. (2011). Barriers to ART adherence \& follow ups among patients attending ART centres in Maharashtra, India. Indian Journal of Medical Research, 134(6), 954. https://doi.org/ 10.4103/0971-5916.92642

Sahu, D., Kumar, P., Chandra, N., Rajan, S., Shukla, D., Venkatesh, S., Nair, S., Kumar, A., Singh, J., Reddy, S., Godbole, S., Elangovan, A., Saha, M., Rai, S., Lakshmi, P. V. M., Gambhir, T., Ammassari, S., Joshi, D., Das, A., ... Vardhana Rao, M. (2020). Findings from the 2017 HIV estimation round \& trend analysis of key indicators 2010-2017: Evidence for prioritising HIV/AIDS programme in India [Original Article]. 151(6), 562-570. https://doi.org/10.4103/ ijmr.IJMR_1619_19

Shukla, S., \& Ramakant, B. (2020). Community networks playing a central role in ensuring access to HIV treatment during India's COVID-19 lockdown. https://www.aidsmap.com/news/apr-2020/ community-networks-playing-central-role-ensuring-access-hivtreatment-during-indias

Smith, J. A., Flowers, P., \& Larkin, M. (2009). Interpretative phenomenological analysis: Theory, method and research (pp. 53-80). Sage Publications Ltd.

Steward, W. T., Bharat, S., Ramakrishna, J., Heylen, E., \& Ekstrand, M. L. (2013). Stigma is associated with delays in seeking care among HIV-infected people in India. Journal of the International Association of Providers of AIDS Care, 12(2), 103-109. https:// doi.org/10.1177/1545109711432315

Sushena, R.-P., Lisa, L., Partha, H., Manisha Reza, P., Bhagya, L., Manjula, R., Akram, P., Syed Hafeez Ur, R., Venukumar, K. T., Venugopal, M. S., Bharat Bhushan, R., \& Robert, L. (2020). Community action for people with HIV and sex workers during the COVID-19 pandemic in India. WHO South-East Asia Journal of Public Health, 9(2), 104-106.

Todrys, K. W., \& Amon, J. J. (2009). Within but without: Human rights and access to HIV prevention and treatment for internal migrants. Globalization and Health, 5(1), 17. https://doi.org/10. 1186/1744-8603-5-17

UNAIDS. (2014). The Gap Report. https://www.unaids.org/en/resou rces/documents/2014/20140716_UNAIDS_gap_report

WHO. (2020). WHO: Access to HIV medicines severely impacted by COVID-19 as AIDS response stalls. Retrieved from https://www. who.int/news/item/06-07-2020-who-access-to-hiv-medicinesseverely-impacted-by-covid-19-as-aids-response-stalls

Publisher's Note Springer Nature remains neutral with regard to jurisdictional claims in published maps and institutional affiliations. 